\title{
Jarbas, o Redentor: um caso clínico de mania apresentado a partir da topologia lacaniana*1
}

\author{
Nympha Amaral*2 \\ Ana Cristina Figueiredo*3
}

\begin{abstract}
Neste artigo visamos solucionar o enigma dos intervalos lúcidos da Psicose maníaco-depressiva a partir de um estudo de caso atendido em um Centro de Atenção Psicossocial (CAPSi). Defendemos que se pode sustentar uma experiência rigorosa do dispositivo analítico em instituição pública. Utilizamos a topologia lacaniana dos nós como método para a construção do caso. Postulamos que nos surtos os nós se rompem e depois se rearranjam entre os três registros - real, simbólico e imaginário - formando um nó não borromeano (nó de trevo) que possibilita uma estabilização do sujeito.
\end{abstract}

Palavras-chave: Psicose maníaco-depressiva, estrutura psicótica, topologia do nó borromeano, psicanálise em instituição pública

*1 Este artigo foi extraído da tese de doutorado de Nympha Amaral, com o título Loucura lúcida: o estatuto estrutural da mania e da melancolia na clínica psicanalítica, apresentada ao Programa de Pós-graduação em Psicanálise da Universidade do Estado do Rio de Janeiro - UERJ em 2014, aluna bolsista da CAPES, sob a orientação da Profa. Dra. Ana Cristina Figueiredo, incluindo a apresentação do caso Jarbas que intitula o texto.

*2 Universidade do Estado do Rio de Janeiro - UERJ (Rio de Janeiro, RJ, Br).

${ }^{* 3}$ Universidade Federal do Rio de Janeiro - UFRJ (Rio de Janeiro, RJ, Br). 
A clínica em serviço territorial de saúde mental é um exemplo de clínica psicanalítica. Esta é nossa premissa. Este artigo pretende demonstrar o funcionamento do dispositivo analítico articulando a topologia lacaniana, como método de construção do caso, ao trabalho em uma instituição pública - Centro de Atenção Psicossocial Infanto-juvenil. Trata-se de um lugar clínico-institucional onde apostamos poder praticar a psicanálise sem que para isso tenhamos que promover adaptações na sua práxis. Se, como previu Freud (1919/1980), ao praticar a psicanálise em instituições públicas e com uma ampla escala da população, nós nos defrontamos com a tarefa de adaptar a técnica psicanalítica a essa nova situação, "qualquer que seja a forma que essa psicoterapia para o povo possa assumir, quaisquer que sejam os elementos dos quais se componha, os seus ingredientes mais efetivos e mais importantes continuarão a ser, certamente, aqueles tomados à psicanálise estrita e não tendenciosa" (p. 108). A clínica lacaniana coloca em cena elementos que estruturam um dispositivo analítico, trocando o espaço geográfico pelos lugares de analista e analisante. A questão é, fundamentalmente, a de saber se podemos comprovar e validar a aplicação da psicanálise enquanto prática clínica nos dispositivos territoriais inaugurados no Brasil pela Reforma Psiquiátrica Brasileira. O resultado a que chegamos em inúmeros casos é positivo: efetivamente aí o psicanalista comparece em seu lugar, e o sujeito comparece, no laço com este analista, na posição de analisante.

É neste sentido que afirmamos que o caso clínico que apresentaremos a seguir é uma cura analítica. Utilizaremos do recurso à topologia lacaniana dos nós como método de construção do caso de modo a poder melhor localizar sua estrutura.

\section{O caso Jarbas}

Jarbas chegou a nós aos 17 anos e por mais de dez anos compareceu regularmente ao CAPSi, tendo havido ao longo do tempo diversas mudanças em seu regime de comparecimento ao serviço, variando, nos 
momentos mais brandos, de consultas semanais com a analista e mensais com o psiquiatra até, no auge dos surtos, em uma permanência diária, de 8 às 17 horas, de segunda a sexta-feira no CAPSi. Além da psicanalista e dos psiquiatras que estiveram diretamente à frente do atendimento, durante as crises a equipe toda do CAPSi participava do trabalho de acompanhar Jarbas em seu cotidiano.

Jarbas foi uma criança levada, depois um adolescente calmo, tímido mas sociável, prestativo e bem-humorado até os 16 anos. Pouco antes dos 17 anos se desencadeia um funcionamento que rompe com tudo o que ele fora: desinibição excessiva, logorreia, insônia, ações temerárias, movimentação incessante, desafio. Essa crise foi sucedida por outra na qual a atitude do jovem é bem mais de desânimo e vergonha. É ainda na esteira desse momento de depressão que Jarbas nos chega. Devemos destacar que esse foi o único episódio melancólico que testemunhamos ao longo de dez anos de tratamento.

Sobre a história da família, a mãe casou-se aos 17 anos e logo engravidou. Tudo corria bem quando aos sete meses de gestação assistiu à morte no parto de uma irmã mais velha e cuja gestação precedera a sua em dois meses. Ela reagiu tendo um episódio de cegueira branca. ${ }^{1}$ Relata ter sido tomada, além da terrível dor da perda, por um pânico de morrer que a atormentou cruelmente até o parto.

O pai de Jarbas abandonou o lar um mês após o nascimento do filho, retornando cinco meses depois. Finalmente, aos dois anos do menino, ele sai de casa definitivamente e essa passa a ser a mais ambivalente de suas referências, sua figura será mote de diversos delírios do rapaz. E ele devotará a vida a suprir o buraco que decorreu da relação com esse pai.

Logo em sua primeira sessão, Jarbas nos traz o momento de desencadeamento de seu primeiro surto: ele, o grande craque de futebol de seu bairro, em uma importante partida provocara, por ter posto a mão na bola dentro da área, sua própria expulsão de campo. Ele jogava em um torneio como o grande reforço do time de meninos da favela. Seu ato impensado fez com que o time perdesse o jogo. E ele, a possibilidade de salvá-lo. Ele foi imediatamente tomado por angústia e, na sequência, surgiu um delírio religioso. Do campo de futebol foi remetido à emergência psiquiátrica: falava coisas sem nexo em um estado de agitação extrema. Permaneceu nesse estado por um

${ }^{1}$ Descrição semelhante à do livro de José Saramago, Ensaio sobre a cegueira. São Paulo: Companhia das Letras, 1995. Consiste em deixar de enxergar não em trevas, mas em excesso de luz. 
mês. Quando finalmente essa condição foi superada, não deixou nenhuma sequela ou sinal, o que fez com que dois meses depois o rapaz suspendesse a medicação por sua própria conta. Todos pensaram ter se tratado de um episódio único, movido pelo estresse da situação. Passados mais dois meses, Jarbas apresentava-se amedrontado, inapetente, em isolamento social, prostrado, motivo pelo qual foi levado ao CAPSi.

A queixa de Jarbas nesse momento se dirigia ao uso de medicação: como pretendia ser jogador de futebol, não poderia usar remédio controlado (sic). Três meses depois, em um atendimento, já mais tranquilo e com um bom vínculo transferencial estabelecido conosco, Jarbas nos conta que dorme junto de sua mãe em uma mesma cama. Perguntamos se a cama em que dormem é de casal. A pergunta desastrada tem imediatamente efeito desestabilizador sobre ele. Vimos, sem que mais nada pudéssemos fazer, que decorreu de nossa intervenção uma tomada das palavras em sua materialidade literal, como costuma ocorrer na psicose. Ele afirma algumas vezes para mim, então, angustiado: "Eu não sou casal com minha mãe".

É trazido no dia subsequente emergencialmente ao CAPSi. Chega afirmando que decidiu ficar sem tomar os remédios. É filho de Deus e já redimiu a humanidade de todo pecado e de todo mal, não precisa de medicações para se curar. Ninguém mais precisa de remédios no mundo após sua ação redentora.

Em um dos dias a seguir, estando em casa por instantes sem a supervisão de um adulto, foge, adentra a vila Vintém ${ }^{2}$ e diz aos traficantes que veio acertar as contas com "o bandido do Celsinho"3 e que vai matá-lo. Os traficantes de drogas, percebendo que se tratava de alguém louco, contentam-se em dar-lhe uma surra exemplar e mandá-lo embora.

Ele ficará pelos próximos três meses com exaltação de humor, agitação psicomotora, aceleração do pensamento, descarrilamento da fala, discurso fortemente megalomaníaco, bastante delirante e insone ao limite do insuportável. A permanência no serviço cinco dias por semana de 8 às 17 horas ao longo de três meses permitiu que o primeiro surto de Jarbas fosse acompanhado sem interná-lo.

${ }^{2}$ Comunidade da Zona Oeste do Município do Rio de Janeiro.

${ }^{3}$ Celso Luís Rodrigues (1961- ), vulgo Celsinho da Vila Vintém, é um criminoso brasileiro, traficante de drogas, fundador da facção criminosa Amigos dos Amigos, atuante na favela da Vila Vintém em Padre Miguel, zona Oeste do Rio de Janeiro. [http://pt.wikipedia.org/wiki/ Celsinho_da_Vila_Vint $\%$ C3\%A9m] 


\section{ARTIGOS}

Ele prosseguiu sendo escutado regularmente. Jarbas nos incluía todo o tempo em seu projeto redentor, delegando-nos a função de auxiliá-lo em sua missão. Interviemos tentando protegê-lo nos momentos mais agudos e, nos raros instantes de pacificação, sublinhando e resguardando os sentidos produzidos por ele. O trabalho analítico, entretanto, só avançava de modo notável nos intervalos lúcidos entre os surtos, fazendo uso do que surgira nestes, quando a produção de fala era bastante significativa. Resgatávamos esses ditos no depois; Jarbas os reconhecia e os integrava a si.

Nos três primeiros anos de tratamento Jarbas teve um surto maníaco por ano. Seu delírio era marcado pela megalomania religiosa: ele é Jesus Cristo, ele já eliminou todo o mal do mundo, ele e todos os outros pacientes do mundo não precisam mais tomar remédios, pois todo o mal foi eliminado e não é mais preciso usar a química. Sua recuperação era sempre total, sem marcas e deixava o rapaz extremamente envergonhado ao se lembrar do que havia feito. O quadro maníaco de Jarbas é, portanto, intercalado por períodos de desconcertante lucidez, alguns períodos extremamente longos, nos quais ele fez análise regularmente, uma vez por semana.

Esse processo conheceu diversas fases. Em uma delas, o trabalho de Jarbas girou em torno da questão: o que me faz enlouquecer? Jarbas é evangélico e, sempre que surta é a partir de uma excessiva aproximação da Igreja. Ele tinha formulado em análise, a princípio, um impasse: como ser religioso se a religião é um risco? Seguindo suas associações chegou a concluir que sempre que surtou estava em apuros em sua vida amorosa. Esse fio associativo leva Jarbas a formular que seu problema, então, não é religioso, como pensara, mas com o sexo.

Em seus períodos lúcidos ele traz para as sessões frequentemente uma divisão, de aparência 'obsessiva', que contrapõe essa conclusão (meu problema é com o sexo) à verdade bíblica (sexo fora do casamento é impuro). Tem, a princípio, convicção de que, quando faz sexo, Deus o pune atrasando sua vida. Depois me pergunta: "É Deus ou sou eu que fico tão perturbado que faço um monte de merda só pra me dar mal?". Ele diz: "(...) fiquei maluco ali por causa da culpa. Não é nem a igreja nem o sexo: meu problema é a culpa".

É notável o caráter de punição extrema que o sentimento de culpa adquire na mania, de tal modo que pode parecer difícil diferenciar essas operações daquelas que um supereu feroz apresenta na neurose obsessiva. A escandalosa diferença é que, no extremo, o conflito levava ao surto, à excitação maníaca de caráter psicótico, no caso de Jarbas ricamente acompanhada de delírios por vários meses. A feição de ferocidade do supereu se 
estabelece exclusivamente às expensas do mecanismo da foraclusão, no desconhecimento mesmo da castração do Outro. Trata-se da experiência do Outro como absoluto e de uma defesa contra isso. Assim se erige, como exterioridade, o supereu na mania.

Após algum tempo ele tem novamente uma grave crise que beira a tentativa de suicídio: ele caminha de Realengo ao Recreio dos Bandeirantes para cumprir o propósito de atirar nas águas seu telefone celular e jogar-se ao mar "para chegar à África". É salvo pelos bombeiros e levado à internação psiquiátrica. Ao fazer uma visita ao hospital, pergunto o que o tinha levado a esses atos: ele diz que, como foi nesta praia que seus pais se separaram, fora lá no intuito de reatar a relação de ambos. Disse ainda que tinha arrancado todas as placas de sinalização do local (que indicavam perigo e proibiam o banho ali) para que não houvesse nenhum impedimento e que ele estava ali para salvar as pessoas. Essa fala, em um momento de exaltação extrema, é seguida por outra, no mesmo humor exaltado, mas de conteúdo distinto: fala que sua vida não tem sentido e que tanto faz viver ou morrer quando se tem Cristo no coração. Esse fragmento de discurso do paciente parece exemplar quanto ao germe melancólico embutido no surto maníaco: há uma empreitada tão megalomaníaca quanto sabidamente impossível de realizar em seu delírio. Para poder destacar do eu o objeto aí encravado é preciso atravessar com o corpo uma moldura de janela ou a imensidão do mar. É notável que seja preciso levar seu corpo quase ao afogamento para promover o reatamento delirante entre o pai e a mãe e promover a separação selvagem entre sujeito e objeto. É seu corpo que ele oferece aí, como uma fracassada suplência paterna.

Outro fragmento que nos parece relevante trazer ocorreu na saída do último surto que testemunhamos. Percebemos em sua fala que pela primeira vez a Igreja se configurou como um Outro ao qual ele pode escolher desobedecer ou burlar. Na operação foraclusiva que estrutura sua mania, o sujeito recusa a castração do Outro. Como sabemos, é precisamente da castração do Outro que resulta o destacamento do objeto $a,{ }^{4}$ aquilo mesmo que permitiria ao sujeito, no caso da neurose, estruturar-se a partir da constituição do fantasma que é, ele próprio, masoquista. Não havendo exteriorização do objeto, o que permite o estabelecimento do fantasma, o sujeito fica impedido

${ }^{4}$ A esse respeito, ver as operações de alienação e separação conforme Lacan apresenta em seu Seminário 11, Os quatro conceitos fundamentais da psicanálise. 


\section{ARTIGOS}

de perceber como "interno", ou nos termos de Lacan (1956-1957/1998) em seu Seminário 4, como "introjetado", o masoquismo originário, fundador de sua constituição, de sua condição de objeto. Ora, a exteriorização do masoquismo, como sabemos, é o sadismo. Com o advento constitucional da foraclusão, entretanto, não é enquanto do sujeito que o sadismo se apresenta, mas é como pertencente ao Outro que ele comparece. O supereu fica "externo" e desde essa exterioridade, absoluto e esmagador, pois tomava de empréstimo a face de um Outro absoluto. Então inicialmente o que ocorria a Jarbas era que uma vez ultrapassado o momento de invasão desse Outro que o surto maníaco representa, o sujeito ficava por um breve lapso de tempo livre da presença crítica, maciça do Outro, em um momento de lucidez particularmente aguda e sem culpa alguma.

Em uma primeira virada decisiva da análise, a Igreja passa a ganhar o caráter de uma baliza que serve de barra à ameaça de um gozo devastador, um lugar que seria terceiro na relação profundamente incestuosa de Jarbas com sua mãe. A Igreja, que se tornava, em uma aproximação maior, a boca aberta do lobo, o bicho-papão que o traga e devora, ganha aqui outra função. Jarbas então encontra a distância exata para situar a Igreja em sua vida. O que se vê é que aí se tratava do Pai que, tanto na estrutura como na biografia, fora catapultado para fora da cena, perdendo sua possibilidade de intervir verdadeiramente como terceiro entre o Outro materno devorador e o sujeito, ficando este à mercê de uma instância que evoca um gozo devastador, esmagador, de caráter onipresente.

À exceção do primeiro surto, desencadeado pela impossibilidade de ser o pequeno herói em uma partida de futebol, todos os surtos subsequentes de Jarbas decorreram de tramas envolvendo sua vida amorosa/sexual e a Igreja Evangélica e tendo como pano de fundo, ao longo dos processos de elaboração das crises, o vínculo mal-sustentado com esse pai idealizado e decaído, do qual ele seria o redentor. A totalidade dos surtos decorreu de alguma ordem de perda, do jogo de futebol ou de uma namorada amada. A Igreja faz as vezes de nó de suplência que sustenta a precária estrutura. Essa posição imaginária virá a ser ocupada também, a partir de seu casamento, por Graça, esposa de Jarbas, tornando a regulação feita pela Igreja menos exclusiva. A esposa veio servir-lhe como elemento de estabilização. Verificamos uma segunda virada, um efeito do trabalho de análise realizado por Jarbas: em uma de suas últimas sessões antes do fim de seu tratamento conosco, ele nos conta, constrangido, que vem há dois anos (portanto desde o casamento) sofrendo de grave ejaculação precoce, o que na prática fazia com que rara e incompletamente 
conseguisse penetrar o corpo da esposa. Essa é uma forma inteiramente outra de regulação.

Compreendemos que, a partir de uma segunda virada feita com a análise, os efeitos invasivos desse Outro mãe/Igreja, ao deslizarem para a figura da esposa puderam se revestir de um artifício de barragem do gozo absoluto: o corpo inteiro em agitação é sucedido pelo pênis incontinente. Longe de isso ser uma teoria geral da ejaculação precoce é, ao contrário, a surpreendente e peculiar condição de colocação em funcionamento de um arremedo de inconsciente, suplência de inconsciente forjada através do trabalho de análise e que faz as vezes de um sintoma no corpo que parece estabilizar Jarbas, ainda que à custa de certa infelicidade em sua vida sexual.

Verificamos aqui que os elementos que estão presentes na neurose encontram-se, arranjados de outra forma, igualmente presentes na psicose. E passíveis de rearranjos pelo trabalho de análise. Ao que parece, os dez anos de análise ajudaram-no a remanejar suas estratégias de gozo e amarrar o nó R.S.I. (Real, Simbólico e Imaginário) de modo a manter distintos os três registros que, por sua peculiar condição de estrutura, viam-se muitas vezes indiferenciados.

\section{Uma topologia para a loucura lúcida}

Nossas questões iniciais ao atender Jarbas se dirigiam tanto à condição estrutural de sua patologia, que nomeamos Psicose maníaco-depressiva (PMD), hoje classificada na psiquiatria como 'transtorno bipolar com sintomas psicóticos', quanto à descoberta de um operador que servisse de suplência nos intervalos lúcidos, permitindo ao sujeito, nesses momentos, um funcionamento sem as marcas da psicose. Perguntávamos também qual seria o caráter do que opera a partir da análise: onde e como se insere o analista na cura do maníaco/melancólico e como pode dar conta dos efeitos que decorrem da cura?

Sabemos de saída que o rearranjo do PMD faz exceção àquele da via do delírio como recurso de reconstrução do mundo mesmo quando nessa há delírio constituído. Parte da resposta à nossa questão de pesquisa aparece suficientemente clara na elaboração de Lacan e dos autores contemporâneos: a PMD é de fato uma psicose e tanto seu mecanismo de constituição é de ordem foraclusiva quanto o gozo que daí advém é fora do registro fálico, não se inscrevendo o maníaco/melancólico na ordem do discurso por não 
transitar na cadeia de significantes entre $\mathrm{S}_{1}$ e $\mathrm{S}_{2}$. Ele fica estancado, seja na fuga vertiginosa, seja na paralisia absoluta, em um só e mesmo sentido que incide infinitas vezes na repetição do mesmo $S_{1}$. Para esse fim, os ditames não dialetizáveis "Nada faz sentido" ou "Tenho a plena potência" se equivalem como resultantes da não função de $a$. O rechaço do inconsciente promove, por um lado, a não função de $\mathrm{S}_{1}$ como ponto de basta e, por outro, leva o sujeito a ser banido do conjunto significante $\mathrm{S}_{2}$.

Os efeitos desse arranjo se fazem sentir de modo notável sobre o supereu. Nossa suposição é de que na PMD o supereu, pela não extração de $a$ no campo do Outro, não consegue se constituir como instância entre o simbólico e o real, não possuindo, então, caráter inconsciente. Ele é uma das faces daquilo que retorna desde fora, do real, a partir do rechaço da linguagem. E o faz de modo invasivo, através de um mandamento de ação ininterrupta, na excitação maníaca ou no jugo da completa inação e da autoacusação levada não raro até o suicídio, na melancolia. Sustentamos que o supereu na PMD se alterna como uma interioridade, aos moldes da neurose, nos intervalos lúcidos, e como uma exterioridade que empuxa/leva ao ato, nos surtos maníaco e melancólico. O maníaco, que não consegue se valer do Ideal do eu, recorre a uma derrisão imaginária deste, sob a forma da norma social, como suporte entre os surtos para um funcionamento dentro do que poderíamos chamar aproximadamente de adequado.

O momento lógico da constituição do sujeito, no qual faz incidência o rechaço do inconsciente é, para nós, contemporâneo ao da identificação mais primitiva, aquela que promove a constituição das instâncias ideais. Poderíamos então afirmar que se trata, na PMD, de uma foraclusão logicamente anterior àquela que resulta em uma paranoia. Na mania/melancolia são legíveis os efeitos de uma desamarração entre simbólico e imaginário, pois falta ao corpo, de onde o objeto deveria ter se destacado, o buraco simbólico que o torifica ${ }^{5}$ (Cancina, 1993).

A topologia do nó borromeano utilizada por Lacan a partir do seminário $\mathrm{XX}$ nos diz que os nós apontam as diferentes soluções a que o falasser pode recorrer para se escrever. Essa solução é sempre singular, tanto quanto o é a apropriação que é alíngua, operação do sujeito a partir do conjunto da linguagem, de sua estrutura enquanto inconsciente. Na medida em que o

${ }^{5} \mathrm{Ou}$ seja, o faz funcionar como a figura topológica do toro. 
nó não é nem um modelo nem uma representação, mas a criação mesma do sujeito, a escrita do nó tem função literal; é a notação peculiar de seu gozo.

Uma das noções que [Lacan] utiliza com frequência nesses dois seminários [R.S.I. e O Sinthoma] é a de lapso ou erro do nó. Em relação a esse lapso, Lacan fala na possibilidade de uma reparação que vai ganhar, a partir de seus estudos sobre Joyce, o estatuto de sinthoma, invenção do sujeito que suplencia o erro apontado. As diferentes versões de erros e suplências mostrados por Lacan nos auxiliam a pensar o diagnóstico e a clínica com a psicose. (Guerra, 2007, p. 172)

O erro específico, no caso da PMD, é a amputação do simbólico, o rechaço da linguagem in totum que priva o sujeito, se não do simbólico, de sua função enquanto elo da tríade RSI. O sujeito vive à expensa de um arremedo de simbólico que configura os intervalos lúcidos, mas que pode, diante de qualquer perda que evidencie a inexistência do furo do simbólico, desmoronar. E há os casos daqueles que demenciam sob a feição maníaca ou deprimem inexoravelmente e se matam, dando nesses casos o testemunho da inexistência mínima de um arremedo para o nó. 492 O supereu, que consideramos anteriormente "uma interioridade com suplência que chamaremos aqui de "inconsciente de prótese" ou de falso $\mathrm{S}_{2}$. Será ela que, colocada entre imaginário e simbólico, permitirá a construção de um falso nó de trevo que se manterá amarrado como se fosse borromeano, sem o ser.

$\mathrm{O}$ que segue como uma constante no ensino de Lacan desde os primórdios é que, por mais distinta que seja a solução proposta, a psicose se articula a uma carência de pai. Pai, por definição, é um elemento que marca a falta na estrutura. Entretanto, a criação que constitui a amarração do psicótico revela uma demissão paterna para a qual o sujeito precisará inventar um arremedo, caso contrário isso não se aguenta. No elo que suplencia o falso nó na PMD, o saber inconsciente de prótese assume a nominação de um supereu externo, depositado em um elemento da vida do sujeito.

No caso de Jarbas, o pai de prótese atendia pelo nome de Igreja e em colisão com ele, toda amarração se desfazia, sobrando apenas o círculo em uma continuidade RSI indiferenciada. Para ele o nome de $\mathrm{S}_{2}$ foi Igreja ao longo de todo o tempo em que se sustentou em intervalos lúcidos entre os surtos. O trabalho feito diante da analista permitiu o deslocamento do nome de sua suplência, sendo a sutura constituída uma criação do sujeito de caráter sexual para manter estável seu arranjo subjetivo. 
Como nos ensina Lacan, a suplência é a invenção que vem para reparar o erro ou remediar o lapso do nó. E o conserto precisa ser aplicado onde se dá o erro. Mas não será jamais de um nó borromeano que se tratará e sim de um nó simples, feito de uma só corda, com aparência de nó de trevo.

Nó de trevo verdadeiro e o falso nó de trevo da PMD

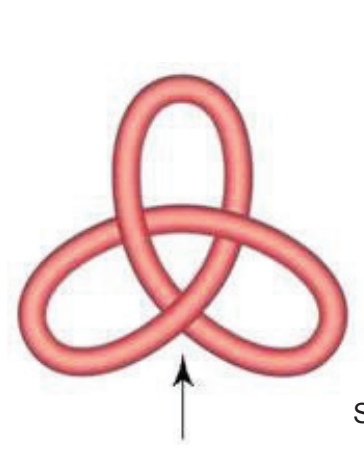

Nó de trevo

verdadeiro

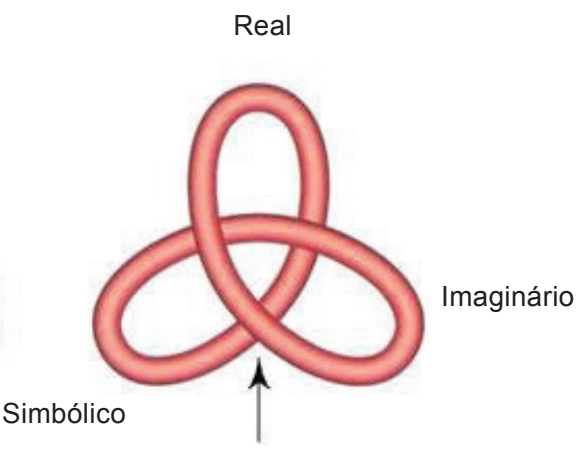

Falso nó de trevo da PMD

Como podemos verificar na figura acima, a imagem da direita traz uma continuidade indiferenciada RSI, de uma única rodela de barbante, sem a verdadeira superposição/costura borromeana entre os três elos, como podemos verificar na figura à esquerda. $\mathrm{O}$ supereu de prótese, $\mathrm{S}_{2}$ que propicia a saída da repetição infinita dos $\mathrm{S}_{1}$ precisa se instalar, no caso da $\mathrm{PMD}$, entre imaginário (corpo em que eu e objeto se confundem) e o simbólico amputado, permitindo, então, ao real ex-sistir e não retornar de modo invasivo.

Simbólico constituído da infinita repetição de $\mathrm{S}_{1}$

\section{A suplência da PMD}

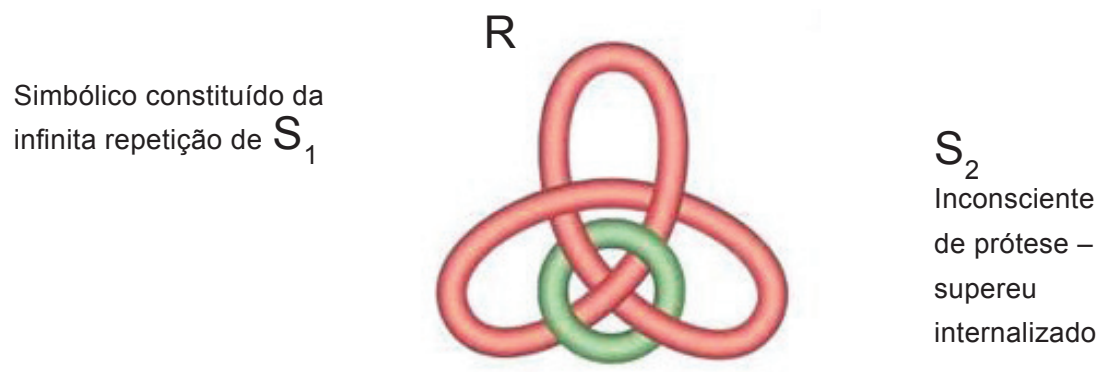


Os intervalos lúcidos decorrem de um elemento qualquer que sirva para o sujeito de amarração externa superegoica mais ou menos estável. Esse um pouco de inconsciente, por fazer trabalhar o sentimento inconsciente de culpa, deixa a rodinha RSI, indistinta, instavelmente amarrada como um falso nó de trevo que, diante de uma perda que revele a ausência do suporte fálico, cai, desmontando o conserto do falso nó. É assim que funcionam os intervalos lúcidos na PMD sem a intervenção do analista.

Sustentamos que o trabalho de análise, por permitir ao sujeito o reconhecimento e a apropriação de seu gozo em um nível inconsciente (não se trata de uma implicação como na neurose), pode vir a construir uma barragem, um elo mais estável para a manutenção do falso nó em uma formatação "consertada". Os efeitos em cascata sobre os registros do real e do simbólico se fazem sentir na medida em que o retorno do rechaçado se estanca, permitindo ao real ex-sistir. A suplência permite ao corpo uma parcialização que não o exija ser todo-peso ou todo-movimento, pela via da manutenção de uma suplência de furo do simbólico, onde se aloja o objeto, temporariamente não confundido com o eu.

Como se pode notar, o que apresentamos aqui como suplência não implicou algo da criação artística como suporte ao qual o sujeito recorreu. Não é simples dizer se a suplência aqui apresentada é da ordem de uma invenção. Jacques Alain Miller (2003) afirma que "nas psicoses maníaco depressivas também há grandes inventores, grandes criadores" (p. 14). Foi de um deslocamento de posição pelo trabalho de análise que a criação da suplência se fez no corpo, em seus modos de funcionar e gozar. Esta é mais uma peculiaridade da PMD em relação às demais psicoses: há na suplência nos entre surtos uma aparente invisibilidade, o que a faz tão enigmática. Principalmente se considerarmos os intervalos lúcidos tão frequentemente reconhecidos como corriqueiros nesses sujeitos.

Consultando os trabalhos de Guerra (2007) e Skriabine (1993b, p. 127-133) sobre topologia, em busca da natureza da suplência que aí opera, chegamos a algumas conclusões. Considerando que o que opera na análise é a redução de um gozo, ou seja, a mudança do trajeto de satisfação se altera e algo do indizível ganha uma alteração real, o analista, tem, então, que incidir na dinâmica desse gozo, no caso do sujeito PMD, para alterar o curto-circuito decorrente da devoração canibalística do objeto, como dizia Abraham.

Como nos lembra Guerra (2007), "se a estrutura da linguagem é a mesma para todos, o uso de lalingua é sempre único para cada sujeito. A articulação que o inconsciente estabelece como forma de gozo é sempre singular 
à maneira como o sujeito se articula na língua mãe" (p. 169). Se todo saber inconsciente é $\mathrm{S}_{2}$, no caso da PMD, é de uma relação ao saber e do lugar do analista na sustentação de um semblante que aí sustente esse $\mathrm{S}_{2}$ como suplência o de que se tratará na cura.

Os nós apontam as diferentes soluções a que cada falasser pode recorrer para se escrever. Essa solução é singular, tão singular quanto alíngua (ou lalingua) é a apropriação que um sujeito singularmente fará do som e letra, do conjunto da estrutura da linguagem enquanto inconsciente. A escrita do nó tem função de letra e escreve a notação peculiar do gozo do sujeito.

É aqui que nó e letra se aproximam. O nó é a escrita com o objeto $a$, é preciso escrevê-lo para saber como ele funciona, nos ensina Lacan. Escrita com objeto-letra que vem de outra parte que não do significante. Ela provém da escrita do traço unário, ao qual Lacan, com a reta infinita do nó borromeano, confere um outro suporte. (...) Sulco, rasura, a escrita é feita da sulcagem do que marca o corpo enquanto gozo, sem nenhuma anterioridade. Letra. É o vazio escavado pela escrita que, como receptáculo, está sempre pronto a acolher o gozo. É essa escrita que o conceito de letra em Lacan inaugura. É a essa escrita que Lacan, com o nó borromeu, provê um suporte. (Guerra, 2007, p. 177)

Skriabine nos lembra, por sua vez, que o gozo e alíngua precedem o Outro da linguagem como estrutura, portanto como saber inconsciente $\mathrm{S}_{2}$. É no encontro com o Outro que o falasser se depara inexoravelmente com sua infalível deficiência estrutural, pois, por não haver o Outro do Outro, a este sempre falta seu próprio significante, foracluído por estrutura. O que aponta para a necessidade de um quarto termo no nó, para as possíveis versões de se nodular RSI. O complexo de Édipo é um quarto termo possível, o sinthoma joyceano é outra possibilidade apontada por Lacan: é preciso um quarto termo para restituir suplementarmente a aparência borromeana do nó quando em sua escrita ele não o é.

Existem algumas possibilidades de suplência: Skriabine (1993b, p. 130) cita três. O sintoma, na neurose, o sinthoma, como em Joyce e a sutura, por ele articulada à paranoia, mas definida como aquela forma de suplência que opera quando os três registros estão em continuidade, que é o que sustentamos aqui.

Propomos, então, a partir do que recolhemos da clínica do caso Jarbas, que a suplência no caso da PMD é da ordem da sutura. A sutura é um dos mecanismos usados pelo sujeito para dar conta da falha no enodamento dos três registros. A suplência de Jarbas é uma sutura porque implica inscrever na parcialidade da superfície do corpo, no destacamento do pênis, uma função 
litoral e não mais um retorno invasivo do real. O gozo fica inscrito e circunscrito, fora do fálico, ao pênis. E seu suporte é a metonímia Igreja/Esposa, novos nomes de um simbólico que mantém os registros distintos entre si, com relativa estabilidade. É esse arremedo de $\mathrm{S}_{2}$, colocado no ponto mesmo em que o nó falha, entre imaginário e simbólico, que permite que ele não se desfaça em uma única corda RSI indiferenciada e se sustente a partir daí como se os três registros se distinguissem, permitindo que então funcionem dessa forma.

A partir do caso acima construído pensamos poder afirmar que há, então, uma suplência específica para a psicose maníaco-depressiva, suplência esta que só se constrói e sustenta a partir do trabalho de análise.

\section{Referências}

Amaral, N. (2014). A loucura lúcida: o estatuto estrutural da mania e da melancolia na clínica psicanalítica. Tese de Doutorado, Programa de Pós-graduação em Psicanálise, Universidade do Estado do Rio de Janeiro - UERJ.

Cancina, P. (1993). Clínica da melancolia. Veredas, Buenos Aires, 1(0)

Elia, L.; Amaral, N. (2012). O que nos autoriza a denominar de psicanálise o que fazemos na instituição pública de saúde mental? Anais da Jornada Anual da Comissão de Enlace Regional de Convergência, Rio de Janeiro. (Mimeo)

Figueiredo, A. C.; Tenório, F. (2002, março). O diagnóstico em psiquiatria e em psicanálise. Revista Latinoamericana de Psicopatologia Fundamental, 5(1), 29-43.

Guerra, A. M. C. (2007). A estabilização psicótica na perspectiva borromeana: criação e suplência. Tese de Doutorado, Universidade Federal do Rio de Janeiro - UFRJ, Rio de Janeiro.

Lacan, J. (1985). O seminário. Livro 11. Os quatro conceitos fundamentais da psicanálise. Rio de Janeiro: Jorge Zahar. (Trabalho original publicado em 1964).

Lacan, J. (1998). O seminário. Livro IV. As relações de objeto. Rio de Janeiro: Jorge Zahar. (Trabalho original publicado em 1956-1957).

Lacan, J. (2007). O seminário. Livro 23. O Sinthoma. Rio de Janeiro: Jorge Zahar. (Trabalho original publicado em 1975-76).

Miller, J-A. (2003). A invenção psicótica. Opção Lacaniana, 36, 6-16.

Skriabine, P. (1993a). Clinique et topologie: Le défaut dans l'univers. La Cause Freudienne, L'énigme \& la Psychose, Publication de l'ÉCF, 23, 117-126.

Skriabine, P. (1993b). La clinique du noeud borromeen. La Cause Freudienne. L'énigme \& la Psychose, 23, 127-133. 


\section{ARTIGOS}

\section{Resumos}

(Jarbas the Redeemer: a clinical case of mania presented based on Lacanian topology)

In this article we aim at solving the enigma of the lucid intervals in the manic depressive psychosis through the clinical case of a patient treated in a Psychosocial Care Center. We believe we can develop a rigorous experience of the analytical treatment in public health services. We use the Lacanian topology of the knots as a method for the construction of the case. We postulate that in and out of the outbreaks the knots untangle and re-entangle between the three registers - the imaginary, the symbolic and the real - forming a non borromean knot (clover knot) that enable the stabilization of the subject.

Key words: Manic Depressive Psychosis, Psychotic structure, Borromean knot topology, Psychoanalysis in public health care

(Jarbas le Rédempteur: un cas clinique de manie présenté a partir de la topologie lacanienne)

Dans cet article nous avons eu pour but de solutionner l'énigme des intervalles lucides de la psychose maniaque dépressive à travers de l'étude d'un cas clinique suivi dans un Centre de Soin Psycho-sociale. Nous croyons qu'on peut maintenir une experience rigoureuse de la psychanalyse dans une institution publique. Nous utilizons la topologie lacanienne des noeuds comme méthode pour construire le cas. Notre proposition est que pendant et après les crises le noeud se rompre et se rénoue entre le réel, le symbolique et l'imaginaire, pas comme un noeud borroméen, mais comme un noeud de trèfle qui permet la stabilization du sujet.

Mots clés: Psychose maniaque-dépressive, Structure psychotique, Topologie du noeud borroméen, Psychanalyse dans l'institution publique

(Jarbas el Redentor: un caso de manía presentado a partir de la topología lacaniana)

En este artículo se tiene por objetivo solucionar el enigma de los intervalos de lucidez de la psicosis maniaco-depresiva en un estudio de caso clínico tratado en un Centro de Atención Psicosocial. Creemos que uno puede sostener una rigurosa experiencia psicoanalítica en una institución pública. Utilizamos la topología lacaniana de los nudos como método para la construcción del caso. Nuestra proposición es que durante e después de los brotes el nudo se rompe e se reanuda entre el real, el simbólico y el imaginario, non como borromeo, pero como un nudo de trébol que permite la estabilización del sujeto.

Palabras clave: Psicosis maníaco depresiva, Estructura psicótica, Topología de los nudos, Psicoanálisis en institución pública 
(Jarbas, der Erlöser: ein Fall von Manie aus der Lacanian Topologie vorgestellt)

In diesem Artikel wollen wir das Rätsel der klaren Intervallen von Psychosis manische Depression aus einer Fallstudie in einem psychosoziale Betreuung Zentrum ( CAPSI). Wir argumentieren, dass man eine strenge psychoanalytischen Erfahrung in einer öffentlichen Einrichtung aufrecht erhalten kann. Gebrauchte Lacansche Topologie der Knoten als ein Verfahren für die Konstruktion des Fälle. Wir postulieren, dass die Ausbrüche wir gebrochen werden und dann zwischen den drei Datensätze neu ordnen - real, symbolischen und imaginären - eine nicht Borromäischen Knoten (Kleeblattknoten) bildet, die eine Stabilisierung des Themas ermöglicht.

Schlüsselwörter: Psychosis Manisch- Depressive, psychotische Struktur, Topologie des Borromäischen Knoten, Die Psychoanalyse in öffentliche Einrichtung

\section{（加尔巴斯，救赎者：用拉康的精神分析拓扑学分析偏执狂症）}

在这篇文章中，我们的目标是通过在一个社会心理治疗中心 (CAPSi) 接受 治疗的一个患者的临床病例研究解决躁狂抑郁间隙性精神病患的清醒一发作之 间的时间间隔。我们相信, 我们可以在公立的精神健康治疗服务中心进行严格 的治疗试验。我们使用拉孔 (Lacan) 的 “连环绳结” 拓扑学解读该病例。我们认 定，在精神病发作期间，“连环绳结” 会断裂，断裂之后，患者自己会自己进 行 “现实, 想象和象征” 的三要素之间的重新组合, 进而形成一个新的 “连环 绳结” (三叶草结)，从而使患者的情绪逐步安静和稳定下来。

关键词: 躁狂-抑郁性精神病, 精神病结构, 连环纠缠绳结的拓扑学, 公立精神 分析医疗机构

Citação/Citation: Amaral, N.; Figueiredo, A. C. C. (2016, setembro). Jarbas, o Redentor: um caso clínico de mania apresentado a partir da topologia lacaniana. Revista Latinoamericana de Psicopatologia Fundamental, 19(3), 483-499.

Editores do artigo/Editors: Profa. Dra. Ana Cristina Costa de Figueiredo e Profa. Dra. Andréa Maris Campos Guerra.

Recebido/Received: 8.9.2015/ 9.8.2015 Aceito/Accepted: 10.12.2015 / 12.10.2015

Copyright: C 2009 Associação Universitária de Pesquisa em Psicopatologia Fundamental/ University Association for Research in Fundamental Psychopathology. Este é um artigo de livre acesso, que permite uso irrestrito, distribuição e reprodução em qualquer meio, desde que o autor e a fonte sejam citados / This is an open-access article, which permits unrestricted use, distribution, and reproduction in any medium, provided the original authors and sources are credited. 
Financiamento/Funding: Pesquisa financiada pela Coordenação de Aperfeiçoamento de Pessoal de Nivel Superior - Capes / The research was funded by the Coordenação de Aperfeiçoamento de Pessoal de Nivel Superior - Capes.

Conflito de interesses/Conflict of interest: Os autores declaram que não há conflito de interesses / The authors have no conflict of interest to declare.

\section{Nympha Amaral}

Pós-doutoranda do Programa de Pós-graduação em Psicanálise do Instituto de Psicologia da Universidade do Estado do Rio de Janeiro - UERJ (Rio de Janeiro, RJ, Br); Coordenadora Técnica do CAPSi CARIM do Instituto de Psiquiatria da Universidade Federal do Rio de Janeiro - UFRJ (Rio de Janeiro, RJ, Br); Psicanalista membro do Laço Analítico Escola de Psicanálise - sede Rio

Praia do Flamengo, 180/302 - Flamengo

22210-030 Rio de Janeiro, RJ, Br

nympha.amaral@gmail.com

\section{Ana Cristina Costa de Figueiredo}

Membro da Associação Universitária de Psicopatologia Fundamental (São Paulo, SP, Br); Supervisora de pós-doutorado da primeira autora; Professora colaboradora do Programa de Pós-graduação em Psicanálise do Instituto de Psicologia da Universidade do Estado do Rio de Janeiro - UERJ (Rio de Janeiro, RJ, Br); Coordenadora do Programa de Mestrado Profissional em Atenção Psicossocial e Professora Associada do Instituto de Psiquiatria da Universidade Federal do Rio de Janeiro - UFRJ; Psicanalista.

Rua Smith de Vasconcelos, 55/101 - Cosme Velho

22241-160 Rio de Janeiro, RJ, Br

anacrisfigueiredo@gmail.com

This is an open-access article, which permits unrestricted use, distribution, the original authors and sources are credited. 